\section{Shear stress in fault zones}

\section{from Barry Kean Atkinson}

SINCE estimates of the shear stress acting on fault zones at major plate boundaries vary by at least an order of magnitude, such fundamental issues as the driving mechanism of plate tectonics and the energetics of crustal faulting remain entirely unresolved'. The shear stresses in the Earth's crust cannot be measured directly, except very close to the surface, so likely stress levels have to be inferred from various secondary lines of evidence.

Laboratory studies of rock friction generally predict that shear stresses on earthquake faults must be at least as high as $100 \mathrm{MPa}$, unless pore fluid pressures approach that due to the overburden. Such high pore fluid pressures may occur transiently during earthquake faulting through a shear-heating-induced thermal expansion of water ${ }^{2}$ but an impressive array of data (summarized in ref. 3 ) shows that pore pressures much greater than hydrostatic will generally only develop in crustal rock sequences containing thick blankets of impervious rocks.

A different level of shear stress is indicated by seismological studies. The average stress drop in crustal earthquakes is usually of the order of $10 \mathrm{MPa}$, or less, irrespective of the strength of the earthquake source, implying that ambient stress levels are also of this order. The key evidence of long-term, low shear stress, probably around $10 \mathrm{MPa}$, comes from the absence of a heat flow anomaly around the San Andreas Fault. A recent comprehensive review ${ }^{4}$ of the latest heatflow data for the western US further supports this view. However, unless relative plate velocities are unreasonably high (tens of $\mathrm{cm} \mathrm{yr}^{-1}$ ), the metamorphic gradients and $\mathrm{K}-\mathrm{Ar}$ ages of rocks along the Alpine Fault of New Zealand are consistent with shear-heating due to a much higher shear stress ${ }^{5}$, of at least $100 \mathrm{MPa}$.

Geological evidence from fault rock textures suggests that both high shear stress $(100 \mathrm{MPa})$ and low shear stress (10 MPa) faulting occur in the upper crust, with the latter more common ${ }^{6}$. High pore fluid pressures are clearly involved in some low stress crustal faulting and higher shear stresses are usually associated with reverse faulting on dry immature fault zones (the Alpine Fault may be exceptionally dry ${ }^{7}$ ).

Even if earthquakes along plate boundaries often occur in an environment where ambient shear stress is low, it could be argued that intraplate earthquakes are different and occur where the ambient shear stress is higher. In the eastern US, for

Barry Kean Atkinson is in the Department of Geology, Royal School of Mines, Imperial College, Prince Consort Road, London SW7 $2 B P$. example, some surficial rocks have higher values of deviatoric stress than are found in the western US, perhaps implying shear stresses of several tens of $\mathrm{MPa}$ at depth. In addition, the moment of earthquake faulting for a given length of fault break is about one order of magnitude higher in some intraplate regions of the US than in western California. The argument has, however, recently been demolished by Raleigh and Evernden ${ }^{8}$ - for the US at least. They point to some little appreciated facts.

First, attenuation rates of horizontally propagating seismic waves with frequencies relevant to intensity observations (1-4 Hz) are grossly different throughout the US. Second, the energy of intensity-relevant frequencies for earthquakes in the conterminous US is solely dependent on fault length and has no relation to attenuation. Finally, for a fixed length of fault break there is a very substantial increase in seismic moment for a change in attenuation from that typical of western California to that typical of eastern US. Thus, moment values have to be explained within models of the Earth that are highly heterogeneous.

These facts can be explained if earthquakes in eastern US occur along fault zones that constitute soft inclusions in an otherwise rigid and strong crust/mantle system. In order to calculate the true moment of an earthquake, allowance must be made for the effective dimensions of a volume in which stress relaxation occurs. Relatively high moments for short fault breaks are only achieved in association with a large volume of relaxation which can be larger than the inclusion. There is no physical anomaly implied by this result, merely a more heterogeneous earth model than is usually used in seismology.

Raleigh and Evernden ${ }^{8}$ also review the evidence for low shear stress on Californian fault zones and conclude that fault zones in all regions of the US are sites of low ambient shear stress and low stress drop.

Fault motion at low shear stresses has been supposed difficult because high pore fluid pressures have been thought to be the only way to reduce the frictional resistance of a fault. Recent research has shown, however, that the chemical effects of pore water may also have a significant effect.

It is notoriously difficult to run deformation experiments in the laboratory at strain rates comparable with those in tectonically loaded fault zones. Yet, such experiments are essential if the range of potential water-weakening reactions are to be assessed. A few years ago, it was shown that stress relaxation experiments ${ }^{9}$ could be used to assess strain rates on fault zones down to about $10^{-10} \mathrm{~s}^{-1}$, within one or two orders of magnitude of some tectonic strain rates but some five orders of magnitude slower than typical laboratory strain rates. Since then this technique has been applied to the study of stress levels on water-weakened faults in a range of crustal rocks ${ }^{10}$

For faults in many wet crustal rocks a dramatic weakening occurs at strain rates below $10^{-7} \mathrm{~s}^{-1}$, probably due to some combination of stress corrosion and diffusional mass transfer. The effect is in addition to any strength reduction due merely to the mechanical effect of high pore fluid pressures. Additional support is given to the stress corrosion hypothesis by the observation that in quartz, the rate of crack growth increases by five orders of magnitude on raising the temperature from 20 to $200^{\circ} \mathrm{C}$ (ref.11).

Some of these experimental results can be extrapolated to conditions thought to occur at depths down to $15 \mathrm{~km}$ along the San Andreas Fault Zone. For sandstone and quartzite, shear stress for sliding under slow, tectonic strain rates of $10^{-11}$ to $10^{-14}$ $\mathrm{s}^{-1}$ is of the order of $10 \mathrm{MPa}$, even if pore water pressure never exceeds hydrostatic. For granite, however, a modest pore water overpressure is required to lower shear stress for sliding into the $10 \mathrm{MPa}$ range.

The explanation for diversity of shear stresses on crustal fault zones may lie in water's different mechanical, thermodynamic and, especially, chemical properties. There is sufficient variation both in the time scale of fault zone processes and in the material properties of crustal rocks which, given the diverse physico-chemical actions of water, could explain the range of shear stress estimates for fault zones. There is a strong case $\mathrm{e}^{8}$ that the environment in which many earthquakes occur is of low shear stress, but with stronger asperities of varying sizes and density of distribution along the fault surface which account for less common, local shear stress of several tens of $\mathrm{MPa}$.

Future work must concentrate on working out the details of potential chemical weakening effects of pore water on rock strength under simulated crustal conditions. Some reliable means will also be required for extrapolating laboratory experiments to the larger strains typical of slip on earthquake fault zones.

\footnotetext{
1. Hanks, T.C. \& Raleigh. C.B. J. geophys. Res. 85 6083 (1980).

2. Sibson, R.H. Nalure 243, 66 (1973)

3. Brace, W.F. Int. J. Rock. Mech. Min. Sci. \& Geomech. Abstr. 17, 241 (1980).

4. Lachenbruch, A.H. \& Sass, J.H. J. geophys. Res. 85 $6186(1980)$.

5. Scholz, C.H., Beavan, J. \& Hanks, T.C. J. geophys. Res. 84, 6770 (1979).

6. Sibson, R.H. J. geophys. Res. 85, 6239 (1980).

Sibson, R.H., White, S.H. \& Atkinson, B.K. Bull. R. Soc N.Z. 18, 55 (1979).

8. Raleigh, C.B. \& Evernden, J. Am. geophys. Un. Geophys. Monogr. 24, 173 (1981).

9. Rutter, E.H. \& Mainprice, D.H. Pageophysics 116, 634 (1978)

10. Atkinson, B.K. \& Dennis, S.M. Trans. Am. geophys. Un. 62, $1036(1981)$.

11. Meredith, P.G.\& Atkinson, B.K. Trans. Am. geophys. Un. 62, 1040 (1981).
} 